\title{
True lies and Moorean redundancy
}

\author{
Alex Wiegmann ${ }^{1}$ (D) Emanuel Viebahn ${ }^{2}$
}

Received: 10 October 2020 / Accepted: 13 August 2021 / Published online: 23 August 2021

(c) The Author(s) 2021

\begin{abstract}
According to the subjective view of lying, speakers can lie by asserting a true proposition, as long as they believe this proposition to be false. This view contrasts with the objective view, according to which lying requires the actual falsity of the proposition asserted. The aim of this paper is to draw attention to pairs of assertions that differ only in intuitively redundant content and to show that such pairs of assertions are a reason to favour the subjective view of lying over the objective one.
\end{abstract}

Keywords Definition of lying $\cdot$ Moore's paradox $\cdot$ Moorean redundancy $\cdot$ Subjective view of lying $\cdot$ Objective view of lying

\section{Introduction}

Does lying require falsity? According to the traditional definition of lying accepted by many philosophers, only believed falsity matters:

A lies to B if and only if there is a proposition p such that:

(L1) A asserts $p$ to $B$, and.

(L2) A believes that $\mathrm{p}$ is false. ${ }^{1}$

The traditional definition thus entails a subjective view of lying, on which a speaker can lie by asserting a true proposition, as long as the speaker believes that the

\footnotetext{
1 Among the theorists who accept a definition of this kind are Chisholm \& Feehan (1977: p. 152), Williams (2002: p. 96), Fallis (2009), Stokke (2018), Maitra (2018), Garcia-Carpintero (2018) and Pepp (2019). Some theorists would add a third clause that requires an intention to deceive. Whether lying requires an intention to deceive is not important for present purposes.
}

Alex Wiegmann and Emanuel Viebahn have contributed equally to this work.

Alex Wiegmann

alexander.wiegmann@ruhr-uni-bochum.de

1 Institute for Philosophy II, Ruhr University Bochum, Universitätsstraße 150, 44801 Bochum, Germany

2 Institut für Philosophie, Humboldt-Universität zu Berlin, Unter den Linden 6, 10099 Berlin, Germany 
proposition asserted is false. Several theorists have attacked this view and have argued for an objective view of lying, according to which lying does require the actual falsity of the proposition asserted. Most objectivists hold that lying requires both believed falsity and actual falsity (see e.g. Coleman \& Kay, 1981, Rott, 2003, Carson, 2006: p. 285, 2010: pp. 15-17 and Turri \& Turri, 2015, 2021, Benton, 2019, Holguín, 2021), though some have argued that only actual falsity is required (Sweetser, 1987: p. 50).

The debate between subjectivists and objectivists is dominated by arguments based on intuitions about individual cases. Many authors have argued for one of the aforementioned views by presenting cases involving a discrepancy between believed and actual falsity and reporting their own intuitions about these cases. ${ }^{2}$ Others have conducted empirical investigations to find out how ordinary speakers classify such cases and have argued that their findings support either a subjective or an objective view of lying. ${ }^{3}$ Only rarely do theorists provide arguments for one or the other view that are not based on individual cases. ${ }^{4}$

We would like to offer an argument for the subjective view of lying that is neither based on intuitions about individual cases, nor on empirical studies, but rather on intuitions about a class of pairs of assertions, where the first and the second assertion in each pair differ only in redundant content. Intuitively, the addition of such content to an assertion should not make a difference to whether the assertion is a lie. However, we will bring out that such a difference is predicted by the objective view of lying, which classifies the first assertion in each pair as a non-lie, but the second as a lie. As the subjective view does not lead to similarly problematic predictions, intuitions about these pairs of assertions speak against the objective view.

\section{Failed lies and Moorean redundancy}

In this section, we will introduce cases of failed lies and the notion of Moorean redundancy, in order to characterise the relevant class of pairs assertions for which subjective and objective views of lying make differing predictions.

To begin with, let us consider cases for which the objective view and the subjective view deliver diverging lie-verdicts. Such cases have the following structure:

- A asserts p to B.

- A believes $\mathrm{p}$ to be false.

\footnotetext{
${ }^{2}$ See e.g. Fallis (2009: p. 39), Saul (2012: pp. 5-6) and Stokke (2018: p. 34) for such case-based arguments in favour of the subjective view and Carson (2006: p. 285, 2010: pp. 15-17) for a case-based argument in favour of the objective view. Holguín (2021) argues that the infelicity of certain sentences supports the objective view.

${ }^{3}$ See e.g. Coleman \& Kay (1981), Turri and Turri $(2015,2021)$ and Wiegmann et al (2016). An overview of relevant studies is provided by Wiegmann \& Meibauer (2019).

${ }^{4}$ But see Augustine (395) and Bolzano (1810) for brief arguments in favour of the subjective view, and Turri \& Turri (2021: p. 758) in favour of the objective view. Bolzano's argument is discussed by Künne (2019: pp. 224-225).
} 
- $\mathrm{p}$ is in fact true.

For the purpose of illustration, consider the following case:

On a Saturday morning, Adam wants to watch a movie with Berta. Berta, however, would rather visit a national park if it is not raining. Hence, Adam looks at his weather app, which shows no rain in the region of the national park. Despite believing that it is not raining, Adam tells Berta that it is raining. Unbeknownst to Adam, the weather app is not working properly and it is actually raining.

In short:

Berta: 'Is it raining?'

Adam, believing that it is not raining: 'It is raining.'

In fact, it is raining.

One might refer to the assertions in these kinds of cases as failed lies. The objective view entails that the fact that $\mathrm{p}$ is true prevents A's assertion from being a lie. Accordingly, these assertions might be described as failed lies because a lie was attempted but the assertion failed to be a lie. By contrast, the subjective view entails that believed-false assertions are lies-even if they are actually true. So, from the perspective of the subjective view, such assertions are really lies. Nonetheless, they can be described as failed because the speaker intends to assert something false but fails to do so. This, in turn, means that the speaker will not achieve her aim of causing a false belief in the addressee.

Next, we want to draw attention to assertions that are very similar to the failed lies we just considered and differ from them only through the addition of certain redundant content. To do so let us take a brief look at assertions that exhibit the phenomenon known as Moore's paradox (MP). Such assertions come in two different forms. In the omissive variant, they have the following form:

p \& I do not believe that p. (E.g., 'It is raining and I do not believe that it is raining').

In the commissive variant, the form is as follows:

p \& I believe that not-p. (E.g., 'It is raining and I believe that it is not raining').

Let us call assertions of both kinds Moorean assertions and let us refer to the first half of these assertions ('p') as the fact-part, and to the second half ('I do not believe that p' and 'I believe that not-p', respectively) as the belief-part.

Moorean assertions are considered to be paradoxical because as assertions (as a move in a conversation) they are absurd and infelicitous, although they might well be true. While the jury is still out on how to best resolve this paradox, it is widely agreed that Moorean assertions involve some kind of contradiction, even though there is no contradiction in the content of what is asserted or believed. ${ }^{5}$ To

\footnotetext{
5 See Moore $(1942,1944)$ for the original presentation of the paradox and Williams (2015) for a recent overview of responses.
} 
distinguish a contradiction in content, e.g., 'p \& not-p', from the kind of contradiction that is triggered by Moorean assertions, let us call the former a content contradiction and the latter a Moorean contradiction. A content contradiction of ' $p$ \& not-p' can be resolved by removing the negation included in the second part of the conjunction, leading to redundancy of the asserted content in the form of ' $p \& p$ '. This observation suggests that removing or cancelling out the negation in the second part (the belief-part) of Moorean assertions could lead to a certain kind of redundancy, which might be called Moorean redundancy. ${ }^{6}$

Moorean assertions of the omissive form can be transformed into what we will call redundant assertions by modifying the belief-part from 'I do not believe that p' to 'I believe that p', resulting in:

p \& I believe that p. (E.g., 'It is raining and I believe that it is raining').

Moorean assertions of the commissive variant can be turned into redundant assertions by adding a negation to the belief-part:

p \& I do not believe that not-p. (E.g., 'It is raining and I do not believe that it is not raining').

These assertions raise a puzzle that is similar to the original Moorean paradox: as assertions they are infelicitous or at least odd, although the truth-value of the factpart and the belief-part might differ. The puzzle differs from the original paradox in that the infelicity or oddness is due to redundancy, not contradictoriness. ${ }^{7}$

Now let us apply Moorean redundancy to cases of failed lies in order to create cases of redundant failed lies. First, the redundancy derived from the omissive version of MP. In such a case, the speaker not only asserts $p$, but additionally asserts that she believes p. In our example:

Berta: 'Is it raining?'.

Adam, believing that it is not raining: 'It is raining and I believe that it is raining.'

In fact, it is raining.

By adding 'and I believe that it is raining', Adam indeed seems to add only redundant information to his assertion that it is raining. The same picture arises if we apply Moorean redundancy derived from the commissive version of the MP. Now, the speaker not only asserts $\mathrm{p}$, but additionally that he does not believe not-p. In our example:

Berta: 'Is it raining?'.

\footnotetext{
6 This label is used by Gibbons (2013: p. 279), who provides a brief discussion of the matter. Also see Freitag \& Yolcu (2021) for a recent discussion of Moorean redundancy.

7 While the infelicity is present in most ordinary assertoric contexts, there are some special contexts in which it disappears, as an anonymous reviewer pointed out. For example, in a profession of faith, it would be felicitous to make an assertion of the following kind: 'Jesus is my Lord and Saviour, and I believe Jesus is my Lord and Saviour.' We will be concerned with ordinary assertoric contexts for now, but will return to felicitous redundancies below.
} 
Adam, believing that it is not raining: 'It is raining and I do not believe that it is not raining.'

In fact, it is raining.

Again, the added material 'and I do not believe that it is not raining' is redundant. Just like other assertions involving Moorean redundancy, redundant failed lies of the kind described sound infelicitous or odd, and this infelicity or oddness can be traced back to the redundancy: an utterance of 'It is raining and I believe that it is raining,' sounds infelicitous or odd because of the addition of redundant material.

It is a different question why the additions sound redundant and thus lead to infelicity. Although we do not want to commit to an answer to this question, it is worth considering central views of assertion to outline the space of possible answers.

Probably the most straightforward account of Moorean redundancy is offered by expressive accounts of assertion, such as that offered by Bach and Harnish (1979: p. 42). Bach \& Harnish hold that to assert p simply is to express the belief $\mathrm{p}$ (and the intention that the hearer believe p). On such an account of assertion, it is obvious why the additions in both the omissive and the commissive versions do not add anything that was not already expressed be the original assertion. If a speaker has asserted $\mathrm{p}$ and thereby expressed that she believes $\mathrm{p}$, then it is redundant to follow up with an assertion that she believes $\mathrm{p}$ (or does not believe not-p).

Expressive accounts of assertion belong to a larger class of representational views of assertion, which entail that in asserting $\mathrm{p}$, the speaker represents herself as believing p. In general, representational views have little difficulty accounting for the impression of redundancy. The explanation goes along the lines just given: if a speaker has represented herself as believing $\mathrm{p}$ (through asserting $\mathrm{p}$ ), then it is clearly redundant to subsequently assert that she believes $\mathrm{p}$ (or does not believe not-p). ${ }^{8}$ Representationalism about assertion is directly defended by Black (1952) and Davidson (1984: p. 268) and it is entailed by the views of Unger (1975: pp. 253-270) and Slote (1979: p. 185), who hold that in asserting p speakers represent themselves as knowing p. If Benton and van Elswyk (2020: Sect. 3) are right, then theories positing a knowledge norm of assertion (e.g. Williamson, 2000) must also be construed as representational. There is thus a large group of views of assertion that can easily explain Moorean redundancy.

How about Stalnaker's (1999) common ground approach and commitment-based accounts of assertion in the vein of Peirce (1934) and Brandom (1983)? For these accounts, the explanation of the felt redundancy is not quite as straightforward, but still explanations do seem to be available, as we briefly wish to indicate. According to Stalnaker, an assertion of $\mathrm{p}$ is a proposal to update the common ground with $\mathrm{p}$. Common ground, in turn, is spelled out as follows:

It is common ground that $\mathrm{p}$ in a group if all members accept (for the purpose of the conversation) that $\mathrm{p}$, and all believe that all accept that $\mathrm{p}$, and all believe that all believe that all accept that p, etc. (Stalnaker, 2002: p. 716)

\footnotetext{
${ }^{8}$ For a related expressivist solution see Freitag \& Yolcu (2021: p. 16).
} 
So, on Stalnaker's view, an assertion of $\mathrm{p}$ is a proposal to mutually accept $\mathrm{p}$. Here it is important that the relevant attitude is acceptance, not belief. This makes explaining Moorean redundancy less straightforward. But we can make progress by appealing to Yalcin's notion of conversational tone:

An attitude is the conversational tone of a group of interlocutors just in case it is common knowledge in the group that everyone is to strike this attitude towards the propositions which are common ground. (Yalcin, 2007: p. 1008)

In many conversations, the conversational tone is belief. If it is, then an assertion of $\mathrm{p}$ is a proposal to mutually believe $\mathrm{p}$. But if a speaker has already made this proposal, it is redundant to subsequently propose to mutually believe that the speaker (who is of course a member of the conversational group) believes $\mathrm{p}$ (or does not believe not-p). So, on the Stalnakerian approach to assertion, Moorean redundancy can be explained for assertions featuring belief as a conversational tone.

This leaves commitment-based accounts of assertion. According to such accounts, asserters take on a commitment to defend the content of their assertions. A speaker who asserts $\mathrm{p}$ takes on a commitment to defend $\mathrm{p}$ if challenged. How can commitment-based accounts explain Moorean redundancy? One important observation here is that one "would not normally undertake a commitment to vindicate entitlement to a proposition one does not believe is true" (MacFarlane, 2011: p. 94, see also Rescorla, 2009). This observation justifies why, in general, if someone asserts $\mathrm{p}$, we assume that the asserter believes $\mathrm{p}$ and does not believe not-p (unless we have reasons to doubt the asserter's sincerity). But if commitment-based accounts can explain why this assumption is licensed, then they can also explain the felt redundancy: it is redundant to assert something the addressee will assume anyway.

Of course, more has to be said for a full defence of these explanations, especially on behalf of common ground or commitment-based views of assertion. How can the Stalnakerian approach explain Moorean redundancy when the conversational tone is not belief? Is there an impression of redundancy in these cases? These are interesting questions, but we will not pursue them any further here, as the explanation of the felt redundancy is not of central importance in the current context.

We now have all the ingredients required to specify the relevant class of pairs of assertions that serves as the basis for our argument for the subjective view of lying. Each pair in this class features two assertions: the first is a failed lie, an assertion the speaker believes to be false but that is actually true; the second differs from the first only through the addition of Moorean redundant content, which is either derived from the omissive or the commissive version of the corresponding Moorean assertion. We can return to our concrete example once more to illustrate the assertions in each pair of the class. One pair consists of an assertion of (1) as a failed lie is and an assertion of (2) as its redundant counterpart (derived from the omissive version of the corresponding Moorean assertion): 
(1) It is raining.

(2) It is raining and I believe that it is raining.

A second pair consists of an assertion of (1) as a failed lie is and an assertion of (3) as its redundant counterpart (derived from the commissive version of the corresponding Moorean assertion):

(1) It is raining.

(3) It is raining and I do not believe that it is not raining.

In considering pairs of assertions of this kind (i.e. the pair of (1) and (2) or the pair of (1) and (3)), we have the strong intuition that the first assertion of each pair is a lie if and only if the second assertion of the pair is a lie. Intuitively, the two assertions in each pair do not seem to differ in a way that matters for the question of whether or not they are lies. ${ }^{9}$

\section{Failed lies and Moorean redundancy: subjective vs. objective views of lying}

Now let us consider how the subjective and the objective view classify pairs of failed lies and their redundant counterparts. According to the subjective view, a speaker lies with both assertions of each pair. As mentioned above, the subjective view counts cases of (simple) failed lies as lies, as it entails that the actual truth of an assertion is irrelevant to whether or not the assertion is a lie. (Failed lies are failed because the speaker aims to assert something false, but fails to do so). If Adam asserts that it is raining while believing that it is not raining, he is lying, regardless of whether or not it is in fact raining. The addition of the Moorean redundant material 'and I believe that p' or 'and I do not believe that not-p' changes nothing about this verdict: if the speaker is lying in the first assertion of a pair, she is also lying in the second assertion of the pair. ${ }^{10}$ And this seems to be the right result, given the intuitions we have just reported.

The objective view, however, leads to a different prediction. In the first assertion of each pair, the truth of $\mathrm{p}$ prevents the speaker from lying: the requirement of asserting an actual falsehood is not met. (Failed lies are failed because they fail

\footnotetext{
9 This intuition is shared by a range of people with whom we have discussed the cases, as well as by two anonymous reviewers. One anonymous reviewer did not share the intuition and, as a result, was not swayed by our argument for the subjective view. We acknowledge that intuitions on the matter are unlikely to be univocal. However, we do think that there are reasons to believe that the intuition in question is widely held and that this suffices for present purposes. To confirm this view, an empirical study would be needed, which we do hope to carry out, but which goes beyond the scope of this paper.

10 To rule out potential problems arising from cases in which speakers believe $\mathrm{p}$ to be false but do not believe that they believe $\mathrm{p}$ to be false, we can restrict our attention to cases in which speakers do have the right introspective beliefs, i.e. cases in which they correctly believe that they believe $\mathrm{p}$ to be false. Thanks to an anonymous reviewer for alerting us to this point.
} 
to be lies). In the second assertion of each pair, the speaker additionally asserts the belief-part 'and I believe that p' (or 'and I do not believe that not-p'). Since the belief-part (and thus the entire assertion) is false - the fact that it is actually raining does not prevent the assertion of 'It is raining and I believe that it is raining' or 'It is raining and I do not believe that it is not raining' from being false-the requirement of actual falsity is now met. The objective view is thus committed to different lieverdicts for pairs of failed lies and their Moore-redundant counterparts: adding the Moorean redundant material suffices to turn a non-lie into a lie.

Here it is worth emphasising that these problematic verdicts do not concern individual cases, but a whole class of pairs of cases: whenever there is a pair of assertions of a failed lie and a corresponding redundant failed lie, the objective view classifies the former as a non-lie and the latter as a lie. ${ }^{11}$ On the face of it, this is a strong reason against the objective view and in favour of the subjective view.

\section{Objectivist objections}

Are there ways to resist the argument? To begin with, adherents of the objective view of lying might object that that verdicts about redundant assertions should not be given much weight because of their infelicity. Rather, only felicitous assertions should be considered in evaluating definitions of lying. In response, we would like to make two points.

Firstly, it is not clear that only felicitous assertions matter for definitions of lying. It seems quite possible that a single assertion is both infelicitous and a lie. For example, if a speaker makes a grammatical mistake while asserting something she (correctly) believes to be false, then her assertion might be infelicitous. But this infelicity arguably does not prevent her utterance from being a lie - a lie that a definition should classify as such. For example, if Adam's command of English is less than perfect and he utters 'Raining it is,' while (correctly) believing that it is not raining, then he has arguably lied, although his utterance is infelicitous. In that case, however, it is unclear why things should be any different for redundant assertions.

Secondly, there are assertions which are very similar to the redundant assertions we have been considering, but which under the right circumstances are felicitous. For such assertions, the two conjuncts of the assertion have to be put into separate sentences. ${ }^{12}$ This leads to the following general structure:

p. I believe that p. (E.g., 'It is raining. I believe that it is raining').

And it leads to the following variant of our concrete example:

Berta: 'Is it raining?'.

Adam, believing that it is not raining: 'It is raining. I believe that it is raining.'

\footnotetext{
${ }^{11}$ Here we are still restricting our attention to cases in which speakers have the right introspective beliefs.

${ }^{12}$ As mentioned above, there are also special contexts (e.g. professions of faith) in which the singlesentence examples are felicitous.
} 
In fact, it is raining.

In such cases, adding the second sentence to the assertion need not lead to infelicity: for example, if the speaker uses the second sentence to reinforce (insist on) what is asserted with the first sentence, it might be completely fine as a contribution to a conversation. However, even if we consider pairs of assertions and corresponding two-sentence assertions (involving a redundant reinforcement), it seems intuitively wrong to classify the first as non-lies and the second as lies. ${ }^{13}$ Moreover, a similar problem then seems to arise within redundant assertions involving two sentences. If both parts of the assertion are evaluated separately, then the objective view classifies the first as a non-lie and the second as a lie, which again seems to go against intuitions on the matter.

According to a second objection, the objective view is right to treat the first and second assertion in each pair differently, as there is a difference in what is said that matters for whether or not an utterance is a lie. ${ }^{14}$ A natural starting point of this objection is the view that the contents of lies have to be said, where the notion of what is said is construed in a narrow manner so as to exclude conversational implicatures. This view has been defended e.g. by Fallis (2009), Saul (2012) and Stokke (2018), who thereby aim to hold apart cases of lying and cases of mere misleading. The idea is that the distinction between lying and mere misleading aligns with the distinction between saying and conversationally implicating: liars say something they believe to be false, while misleaders put forward a believed-false implicature. Given this view of lying, the objective view might be defended as follows: While the first assertion of each pair somehow conveys the content that the speaker believes $p$, this content is a conversational implicature; what is said by the assertion is merely $p$, and this content is believed to be false, but not in fact false. By contrast, the second assertion of each pair is used to say that the speaker believes $\mathrm{p}$, which is in fact false. Recalcitrant intuitions notwithstanding, the objective view thus correctly captures a difference within in each pair: the first assertion is merely misleading, while the second is a lie.

While this seems like a natural initial reaction on behalf of the objective view, there are two reasons why we do not think that it is promising. Firstly, there is evidence that the first assertion in each pair does not merely conversationally implicate that the speaker believes p. ${ }^{15}$ After all, it is widely held that conversational implicatures must be cancellable: if a content $\mathrm{p}$ is put forward as a conversational implicature by an utterance of a certain sentence, it must be possible to felicitously utter the same sentence (in the same context) with an added 'but not p' or 'but I don't

\footnotetext{
${ }^{13}$ It might also be possible to use the second sentence to weaken the original assertion or to clarify the weakness of the original assertion. In such cases, the objective view also leads to counterintuitive results: while it classifies the simple assertion of $\mathrm{p}$ as a non-lie, it classifies the weakened assertion as a lie. But if verdicts can differ between the simple assertion and the weakened assertion, surely only the opposite distribution of verdicts is plausible (according to which the simple assertion is a lie, while the weakened assertion is a non-lie).

${ }^{14}$ Many thanks to an anonymous reviewer for raising this objection.

${ }^{15}$ Note that Grice considers this possibility and rejects it: "On my account, it will not be true that when I say that $p$, I conversationally implicate that I believe that $p$ " (Grice, 1989: p. 42).
} 
mean to imply p' (cf. Zakkou, 2018: p. 7). But in the current case that clearly isn't possible: after all, adding the cancellation clauses leads us straight to Moore-paradoxical sentences. In our example, these would be the infelicitous 'It is raining, but I don't believe it is raining' and 'It is raining, but I don't mean to imply that I believe it is raining'. That is strong evidence that that the first assertion in each pair does not merely conversationally implicate that the speaker believes $\mathrm{p}$, but conveys this content in a different manner. Even if it is granted that the contents of lies have to be said, where what is said excludes conversational implicatures, the objection thus does not succeed: the first assertion in each pair does not conversationally implicate that the speaker believes $\mathrm{p}$, and thus does not fit with standard cases of misleading. ${ }^{16}$

Secondly, the view that ties lying to what is said has come under attack recently: it has been argued that the content of a lie need not be said and can, indeed, be a conversational implicature. For instance, Viebahn (2017) argues that it is possible to lie while speaking non-literally (for instance using metaphorical or hyperbolical language), and that this is a reason to reject the requirement that the content of a lie has to be said. Instead, lying should be defined in terms of communicative commitment (i.e. liars have to commit to something they believe to be false), where commitment is spelled out in a way that does not require speakers to say $\mathrm{p}$ in order to be committed to $\mathrm{p}$ (cf. Viebahn, 2021). So, for the objection to go through, adherents of the objective view would not only have to show that the speaker in the first assertion of each pair does not say that she believes $\mathrm{p}$, but also that lying should indeed be captured in terms of what is said. ${ }^{17}$

A third potential objection takes the opposite route and argues that, contrary to what our argument assumes, the objective view need not classify the first and second assertion in each pair differently. An initially promising way of supporting such an objection looks to the phenomenon of indirect assertion. While it is commonly assumed that assertion has to be "open, explicit and direct" (Pagin, 2016), several theorists have argued that assertion can be indirect (cf. Bach \& Harnish, 1979: p. 70ff., Green, 2017 and García-Carpintero, 2018). If indirect assertion is possible, which we do not wish to rule out, a speaker who directly asserts $\mathrm{p}$ might thereby

\footnotetext{
16 The anonymous reviewer argued that different versions of the objection are possible, according to which the first assertion in each pair is not used to conversationally implicate that the speaker believes $\mathrm{p}$, but rather carries a conventional implicature with this content or conveys it in yet another way. We are doubtful that conventional implicatures are of help to the objectivist here: those theorists who have discussed conventional implicatures in the context of the lying-misleading distinction (such as Stokke, 2017) hold that conventional implicatures do belong to what is said and can be used to lie; in that case, however, the objectivist would have to classify failed lies as lies, which goes against the spirit of the view. (We discuss this option below). It may be possible to argue that the proposition that the speaker believes $\mathrm{p}$ is conveyed in yet some other way that does not turn the first assertion into a lie (on the objective view of lying), but (as far as we can tell) none of the existing accounts of lying makes room for this possibility, and thus we will move on for now.

17 Indeed, it might be argued that the cases of this paper provide further reasons not to rely on the notion of what is said in defining lying, given that a difference in what is said (between the two assertions of each pair in our class) does not lead to an intuitive difference about whether or not the speaker has lied. While we take an argument of this kind to be promising, we cannot pursue it any further here.
} 
indirectly assert that she believes $\mathrm{p}$. In this way, it might be argued that, even on the objective view, the speaker can be classified as lying when making a believed-false assertion in cases of failed lies. ${ }^{18}$

However, doing so would come at the price of treating failed lies as cases of lying, which would defeat the main purpose of the objective view. Could the objective view resist the argument by treating both kinds of cases as not involving a falsehood? This attempt seems even less promising, because it is hard to deny that an assertion of 'I believe that $\mathrm{p}$ ' is false when the speaker does not believe that $\mathrm{p}$ - the fact that $p$ is actually true is irrelevant for the question of whether or not ' $I$ believe that p' is false. Hence, the objective view seems committed to treating pairs of failed lies and their redundant counterparts differently.

According to the fourth and final objection we will consider here, our paper fails to make a significant contribution to the debate between subjectivists and objectivists, as objectivism is already faced with a number of recalcitrant intuitions about cases that have been discussed in the literature. ${ }^{19}$ While we agree that there are other cases and intuitions that do not fit well with objectivism, we think this objection, too, lacks force. For one thing, the cases and intuitions we discuss do differ from those to be found in the literature. Most existing discussions of the matter focus on individual cases in which speakers assert something they incorrectly believe to be false. Intuitions about such cases are then expressed, which in many cases align with subjectivism and in some cases with objectivism (cf. the articles mentioned in footnote 2). While arguments of this kind might appear similar at first sight, they are crucially different from our argument. To see why, let us make the two lines of argument as parallel as possible. The standard subjectivist strategy could be stated as the claim that there is no intuitive difference between the following two cases:

$\begin{array}{ll}\text { S believes it is not raining. } & \text { S believes that it is not raining. } \\ \text { S says: 'It is raining.' } & \text { S says: 'It is raining.' } \\ \text { It is actually raining. } & \text { It is actually not raining. }\end{array}$

With respect to this pair, subjectivists claim that whether or not it is actually raining should not make a difference for the question of whether the speaker lied. Objectivists deny this and hold that there is an intuitive difference. By contrast, the difference between the pairs we use concerns what the speaker says, while the other facts stay the same.

Secondly, the intuitions we discuss do not concern individual cases or pairs of cases, but rather a class of pairs of assertions, as we note above. This is another contrast with the existing discussions on the matter, which are based on individual cases. So while it is true that certain recalcitrant intuitions troubling the objective

\footnotetext{
18 This objection is incompatible with the view that ties lying to what is said, but could be combined with recent commitment-based approaches, such as those defended by Viebahn $(2020,2021)$ and Reins \& Wiegmann (2021).

19 This objection was put forward by an anonymous reviewer.
} 
view have been discussed before, these are not the kinds of intuitions discussed here. Moorean redundancy leads to an additional problem for the objective view, and not merely to a different version of a problem that was already known.

\section{Conclusion}

To sum up, we have argued for the subjective view of lying and against the objective view of lying by considering pairs of assertions, where a speaker (who incorrectly believes $\mathrm{p}$ to be false) either asserts only $\mathrm{p}$ or redundantly adds to this assertion that he believes p/does not believe not-p. While the redundant addition might make a difference for some aspects of the overall assertion (in particular for its felicity), it is intuitively irrelevant for the question whether the speaker has lied. The subjective view of lying accords with this judgement, classifying both assertions as lies. For the objective view, however, the redundant addition is important: it can turn a nonlie into a lie. In our view, this is a reason to reject the objective view of lying and to accept the subjective view.

Acknowledgements We would like to thank Jörg Meibauer, Steffen Koch, Joachim Horvath, Neri Marsili, and three anonymous reviewers for helpful suggestions. Alex Wiegmann's work on this paper was supported by an Emmy Noether grant of the German Research Foundation (DFG), Project Number 391304769.

Funding Open Access funding enabled and organized by Projekt DEAL.

Open Access This article is licensed under a Creative Commons Attribution 4.0 International License, which permits use, sharing, adaptation, distribution and reproduction in any medium or format, as long as you give appropriate credit to the original author(s) and the source, provide a link to the Creative Commons licence, and indicate if changes were made. The images or other third party material in this article are included in the article's Creative Commons licence, unless indicated otherwise in a credit line to the material. If material is not included in the article's Creative Commons licence and your intended use is not permitted by statutory regulation or exceeds the permitted use, you will need to obtain permission directly from the copyright holder. To view a copy of this licence, visit http://creativecommons.org/licen ses/by/4.0/.

\section{References}

Augustine. (395/2013). De Mendacio. In Opera/Werke, Vol. 50. Edited and translated by Alfons Städele. Schöningh.

Bach, K., \& Harnish, R. (1979). Linguistic communication and speech acts. The MIT Press.

Benton, M. (2019). Lying, belief, and knowledge. In J. Meibauer (Ed.), The oxford handbook of lying (pp. 120-133). Oxford University Press.

Benton, M. A., \& Van Elswyk, P. (2020). Hedged assertion. In S. Goldberg (Ed.), The oxford handbook of assertion (pp. 245-263). Oxford University Press.

Black, M. (1952). Definition, presupposition, and assertion. The Philosophical Review, 61(4), 532.

Bolzano, B. (1810/2007). Über die Wahrhaftigkeit. In Erbauungsreden der Studienjahre 1804/05 bis 1819/20. Ed Edgar Morscher and Kurt F. Strasser. Frommann-Holzboog.

Brandom, R. (1983). Asserting. Noûs, 17(4), 637.

Carson, T. L. (2006). The definition of lying. Nous, 40(2), 284-306.

Carson, T. L. (2010). Lying and deception: Theory and practice. Oxford University Press. 
Chisholm, R. M., \& Feehan, T. D. (1977). The intent to deceive. The Journal of Philosophy, 74(3), $143-159$.

Coleman, L., \& Kay, P. (1981). Prototype semantics: The English word lie. Language, 57(1), $26-44$.

Davidson, D. (1984). Communication and convention. Synthese, 59(1), 3-17.

Fallis, D. (2009). What is lying? Journal of Philosophy, 106(1), 29-56.

Freitag, W., \& Yolcu, N.-M. (2021). An expressivist solution to Moorean paradoxes. Synthese. https://doi. org/10.1007/s11229-020-03012-4.

García-Carpintero, M. (2018). Sneaky assertions. Philosophical Perspectives, 32(1), 188-218.

Gibbons, J. (2013). The norm of belief. Oxford University Press.

Green, M. (2017). Speech acts. In E. N. Zalta (Ed.), Stanford Encyclopedia of Philosophy. https://plato. stanford.edu/archives/win2017/entries/speech-acts/.

Grice, H. P. (1989). Studies in the way of words. Harvard University Press.

Holguín, B. (2021). Lying and knowing. Synthese, 198(6), 5351-5371.

Künne, W. (2019). Bernard Bolzanos Erbauungsreden (und ihre Edition). Academia.

MacFarlane, J. (2011). What is assertion? In J. Brown \& H. Cappelen (Eds.), Assertion: New philosophical essays (pp. 79-96). Oxford University Press.

Maitra, I. (2018). Lying, acting, and asserting. In E. Michaelson \& A. Stokke (Eds.), Lying: Language, knowledge, ethics, and politics (pp. 65-82). Oxford University Press.

Moore, G. E. (1942). A reply to my critics. In P. Schilpp (Ed.), The philosophy of G. E. Moore, pp. 535-677. La Salle, Ill: Open Court.

Moore, G. E. (1944). Russell's theory of descriptions. In P. Schilpp (Ed.), The philosophy of Bertrand Russell (pp. 175-225). Open Court.

Pagin, P. (2016). Assertion. In E. N. Zalta (Ed.), Stanford Encyclopedia of Philosophy. https://plato.stanf ord.edu/archives/win2016/entries/assertion/.

Peirce, C. S. (1934). Belief and judgment. Collected papers of Charles Sanders Peirce. Harvard University Press.

Pepp, J. (2019). The aesthetic significance of the lying-misleading distinction. The British Journal of Aesthetics, 59(3), 289-304.

Reins, L. M., \& Wiegmann, A. (2021). Is lying bound to commitment? Empirically investigating deceptive presuppositions, implicatures, and actions. Cognitive Science., 45(2), e12936.

Rescorla, M. (2009). Assertion and its constitutive norms. Philosophy and Phenomeno-Logical Research, $79,98-130$.

Rott, H. (2003). Der Wert der Wahrheit. In M. Mayer (Ed.), Kulturen der Lüge (pp. 7-34). Böhlau.

Saul, J. M. (2012). Lying, misleading, and what is said: An exploration in philosophy of language and in ethics. Oxford University Press.

Slote, M. (1979). Assertion and belief. In J. Dancy (Ed.), Papers on language and logic (pp. 177-191). Keele University Library.

Stalnaker, R. (1999). Context and content: Essays on intentionality in speech and thought. Oxford University Press.

Stalnaker, R. (2002). Common ground. Linguistics and Philosophy, 25(5/6), 701-721.

Stokke, A. (2017). Conventional implicature, presupposition, and lying. Aristotelian Society Supplementary, 91, 127-147.

Stokke, A. (2018). Lying and insincerity. Oxford University Press.

Sweetser, E. E. (1987). The definition of lie: An examination of the folk models underlying a semantic prototype. In D. Holland \& N. Quinn (Eds.), Cultural models in language and thought (pp. 43-66). Cambridge University Press.

Turri, A., \& Turri, J. (2015). The truth about lying. Cognition, 138, 161-168.

Turri, A., \& Turri, J. (2021). Lying, fast and slow. Synthese, 198, 757-775.

Unger, P. (1975). Ingnorance: A case for skepticism. Oxford University Press.

Viebahn, E. (2017). Non-literal lies. Erkenntnis, 82, 1367-1380.

Viebahn, E. (2020). Lying with presuppositions. Noûs, 54, 731-751.

Viebahn, E. (2021). The lying-misleading distinction: A commitment-based approach. The Journal of Philosophy, 118(6), 289-319.

Wiegmann, A., \& Meibauer, J. (2019). The folk concept of lying. Philosophy Compass, 14, 8.

Wiegmann, A., Samland, J., \& Waldmann, M. R. (2016). Lying despite telling the truth. Cognition, 150, $37-42$.

Williams, B. (2002). Truth and truthfulness: An essay in genealogy. Princeton University Press.

Williams, J. N. (2015). Moore's paradox in speech: A critical survey. Philosophy Compass, 10(1), 10-23. 
Williamson, T. (2000). Knowledge and its limits. Oxford University Press.

Yalcin, S. (2007). Epistemic modals. Mind, 116(464), 983-1026.

Zakkou, J. (2018). The cancellability test for conversational implicatures. Philosophy Compass, 93(3), e12552.

Publisher's Note Springer Nature remains neutral with regard to jurisdictional claims in published maps and institutional affiliations. 